\title{
Efficacy of Positional Release Therapy versus Integrated Neuromuscular Ischemic Technique in the Treatment of Upper Trapezius Trigger Point
} \author{
Noreen $^{6}$ and Muhammad Faizan Hassan ${ }^{7}$ \\ ${ }^{1}$ Senior Lecturer, United College of Physical Therapy \\ ${ }^{2}$ Principal, Isra Institute of Rehabilitation Sciences, Isra University \\ ${ }^{3}$ Principal, College of physical Therapy, JPMC \\ ${ }^{4}$ Principal \& Assistant Professor, United College of Physical Therapy \\ ${ }^{5}$ Senior Lecturer, Ripah College of Rehabilitation Sciences \\ ${ }^{6}$ Physical Therapist, Dr. Essa Lab \\ ${ }^{7}$ Physical Therapist, Ziauddin University
}

Abdul Rashad ${ }^{1 *}$, Muhammad Asif ${ }^{2}$, Riaz Baig Chughtai ${ }^{3}$, Erum Tanveer ${ }^{4}$, Shahab Uddin ${ }^{4}$, Breera Amjad $^{5}$, Alisha

Submission: June 20, 2019; Published: July 08, 2019

*Corresponding author: Abdul Rashad, Senior Lecturer, United College of Physical Therapy, Karachi, Pakistan

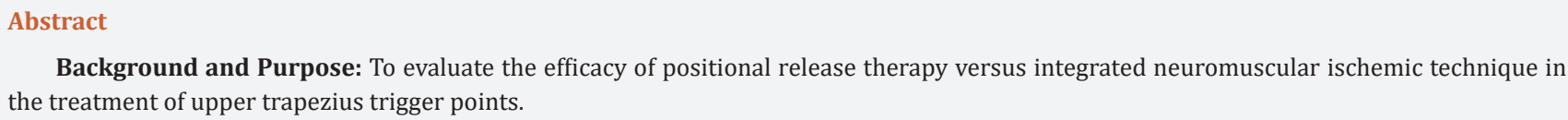

Background and Purpose: To evaluate the efficacy of positional release therapy versus integrated neuromuscular ischemic technique in the treatment of upper trapezius trigger points.

Subject: 40students were selected for the study.

Method: The 40 selected subjects with trapezius trigger points were randomly divided into 2 groups of 20 patients each. All participants who fulfilled inclusion criteria were selected from Isra Institute of Rehabilitation Sciences. Informed consent was taken from students. In both groups, trigger points were identified by the STAR palpation method, assessment Performa was filled up by the therapist and neck range of motion assessed by INCLINOMETER and neck pain was assessed by NUMERIC PAIN SCALE as base line measurement on the first day (pre-test scores) before starting the treatment.

Results: PRT and INIT patients, results showed, among PRT patients NPR before treatment was $4.05 \pm 0.76$ and after treatment it went down significantly to $2.25 \pm 0.79$, similarly among INIT patients mean NPR was $4.4 \pm 1.1$ and after treatment it was $1.4 \pm 0.76$ and differences were statistically significant with p-value less than 0.05 .

Conclusion: The present study was done to find out the effectiveness of INIT versus PRT in the treatment of upper trapezius trigger points. This study endorses that trigger points in trapezius can cause neck pain with restriction in cervical range of motion. Both groups were found to be effective in reducing pain and improving cervical range of motion. However, when both groups were compared, there was a significant improvement in INIT group with greater mean than the PRT group.

Keywords: Trigger Point; Trapezius; Integrated Neuromuscular Inhibition Technique; Positional Release

Abbreviations: PRT: Positional Release technique; SCS: Strain Counter strain; PIR: post-isometric relaxation; INIT: integrated neuromuscular ischemic technique; MET: Muscle Energy Technique

\section{Introduction}

Trapezius fibers like occipital and nuchal passed down but insertion into the clavicle transverse mainly. Fibers from $\mathrm{C} 7$ to $\mathrm{T} 1$ vertebrae distributed diagonally and insert into the acromion process and spine of the scapula and thoracic fibers inserted into the deltoid tubercle of the scapula. Fibers from C7 to T1 vertebrae and the lower half of ligamentum nuchae were the largest. Drawing the scapula and clavicle backwards are action of these fibers rather or to rotate the clavicle and elevates the scapula around the sternoclavicular joint [1]. Myofascial pain syndrome correlated to activate sockets is a no inflammatory ailment of musculoskeletal origin, allied with native discomfort and muscle rigorousness, described by the existence of hyperirritable palpable nodules in the skeletal muscle fibers, which are termed activate points. Myofascial pain syndrome is 
incredibly usual with the local population. Chances of acquiring said ailment can be reaching up to $54 \%$ in the female locality and $45 \%$ in the male locality [2].

Active trigger points produce pain at resting tender on palpation and have referred pain pattern [3-5]. Latent Trps cause weakness and restrict the movement and pain is not spontaneous [5]. There are three portions of trapezius like upper middle and lower trapezius muscle and each portion have two trigger points plus one unusual due to autonomic phenomena. Trigger points of upper trapezius were found most frequently identified in body. Superior trapezius Trps referred ache in post lateral part of the neck, ear, and temple. Sudden trauma, downstairs, falling from height, poor posture, misfit furniture, muscular abuse and longtime immobility are factors due to which trigger points are formed in trapezius muscle [6].

Trigger points can be activated due to numerous factors which include prolonged muscle excess, by the initiation of further Trps like (primary/secondary), infection, emotional issues like (stress/anxiety), trauma, homeostatic imbalance, infections, and smoking [7]. Diagnosis of trigger points depends on examiner's accuracy, experience, teaching and palpation abilities. There is no consent among clinicians concerning physical outcomes. Clinicians accept stiff, intense swelling identified as an active Myofascial trigger point. There is low sensitivity or specificity of digital examination which consider as Gold Standard [8]. Passive or active stretching of the concerned muscle consequents in a pain increase when trigger points are present. Limited muscle stretch. The pain increases when the affected muscle undergoes an isometric contraction and there is a reduced maximum contractile force. Deep sensitivity and dysaesthesia are commonly found in trigger point referral pain zones. Muscle palpation adjacent to active myofascial trigger points feels tense [9].

Positional Release technique (PRT) is a soft tissue application, correspondingly acknowledged as Strain Counter strain (SCS) is a moderate physical management for muscle pain and spasm which include readjusting muscle tone and increasing circulation [10]. Palpate connecting contradictory muscles to localize central and other Trps. Palpable Trps on a consistent measure (enormously sensitive, exact sensitive, temperately sensitive, no painfulness). Do not strain to disrupt the Trps with firm pressure-first dent the skin (1 kg of force). Grasp the position of comfort until fasciculation declines considerably or ends altogether [11]. In neuromuscular inhibition technique a trigger point is situated by palpation, nearly all frequently with the fingers. A trigger point is a confined area of deep hardening. The skilled practitioner will frequently observe a palpable change as a finger pass above the trigger point. Stress on a trigger point will frequently cause twitching in the muscle that within the trigger point. Finger strain is maintained on top of the trigger point, the trigger point will fabricate a pain which refers to an area exterior the muscle which within it. Area doesn't have to be adjacent with the muscle contain the trigger point. There might very well be a number of diverse trigger points and their mention areas may well overlie [12].

A study was done to compare the effectiveness of postisometric relaxation (PIR) along with ultrasound and massage versus integrated neuromuscular ischemic technique (INIT) along with ultrasound and massage in the treatment of trigger point pain of the upper trapezius muscle. Results of this study reveal that subjects with trigger points in the upper trapezius muscle had significant reduction in pain, improvement in ROM and reduction in scores of NPNPQ. This study concluded that in the treatment of trigger point pain in the upper trapezius muscle both treatment techniques were highly effective [13]. In the year 2017 a study was done by Dr. Priyanka Devang Rana et al. to compare the effectiveness of Muscle Energy Technique (MET) versus Positional Release Technique (PRT) in terms of subjective improvement in Pain, Range of Motion and Function in computer workers suffering from trapezius muscle spasm and study concluded that. PRT was a lot of statistically and clinically superior for decreasing VAS pain score, NDI score and rising range of motion and MMT. PRT showed earlier pain relief as compared to MET. So, if patient needs prompt pain relief positional release technique is that the best treatment which may be offered by therapist [14].

\section{Methodology}

The study was experimental (Pre and Post). Setting was Isra Institute of Rehabilitation Sciences Karachi Campus. Both male and female Presence of a taut band in the upper trapezius muscle with an active painful trigger point at its middle, pain is produced upon palpation. Patients complain from neck pain restriction of neck ROM 19 years to 25 years old. The data collection tool was Numeric pain scale Inclinometer was used. The 40 selected subjects with trapezius trigger points were randomly divided into 2 groups of 20 patients each. All participants who fulfilled inclusion criteria were selected from Isra Institute of Rehabilitation Sciences. Informed consent was taken from students. In both groups, trigger points were identified by the STAR palpation method, assessment Performa was filled up by the therapist and neck range of motion assessed by INCLINOMETER and neck pain was assessed by NUMERIC PAIN SCALE as base line measurement on the first day (pre-test scores) before starting the treatment.

The patients in group A and group B received the following treatment

a) Group A-Positional Release Therapy (PRT).

b) Group B-Integrated Neuromuscular Ischemic Technique (INIT).

c) Patients with upper trapezius trigger points received 4 weeks treatment of INIT.

Protocol The study was divided into 3 phases. 
i. $\quad$ Phase (A) Pre-treatment assessment: Baseline outcome measure was NRS scale, ROM.

ii. Phase (B) Intervention phase: INIT was given for 3 days in a week for 4 weeks.

iii. Phase(C) Post- treatment assessment outcome measures were recorded at the end of 4 -weeks [15].

As the primary focus of the INIT approach is to deactivate specific TrPs, the practitioner first identified the TrPs to be treated within the upper trapezius muscle. The subjects were placed in supine to reduce tension in the upper trapezius muscle. Their arm was positioned in slight shoulder abduction with the elbow bent and their hand resting on their stomach. Using a pincer grasp, the practitioner moved throughout the fibers of the upper trapezius and made note of any active TrPs. Once the TrPs were identified treatment began. The therapist again utilized a pincer grasp, placing the thumb and index finger over the active TrP. Slow; increasing levels of pressure were applied until the tissue resistance barrier was identified. Pressure was maintained until a release of the tissue barrier was felt. At that time, pressure was again applied until a new barrier was felt. This process was repeated until tension/tenderness was unable to be identified or $90 \mathrm{~s}$ had elapsed, whichever came first. Treatment duration: 3 sessions per week for 4 weeks. All identified TrPs were treated (Figure 1) [16].

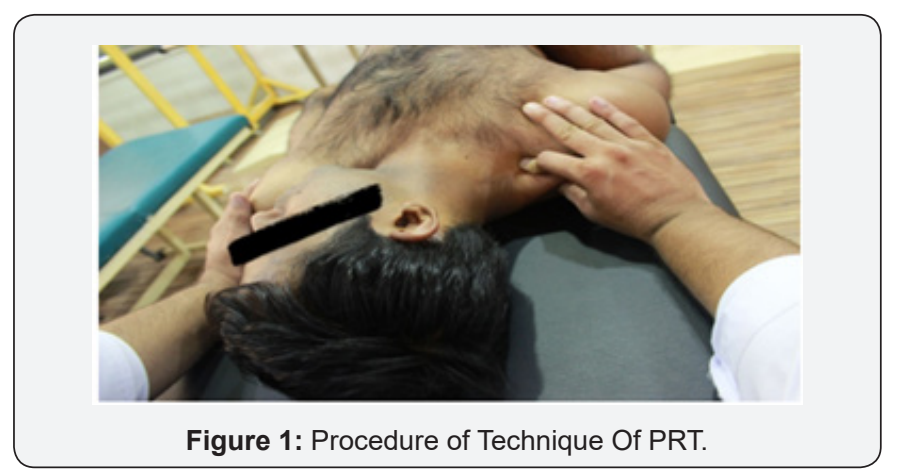

\section{Procedure of Technique of PRT}

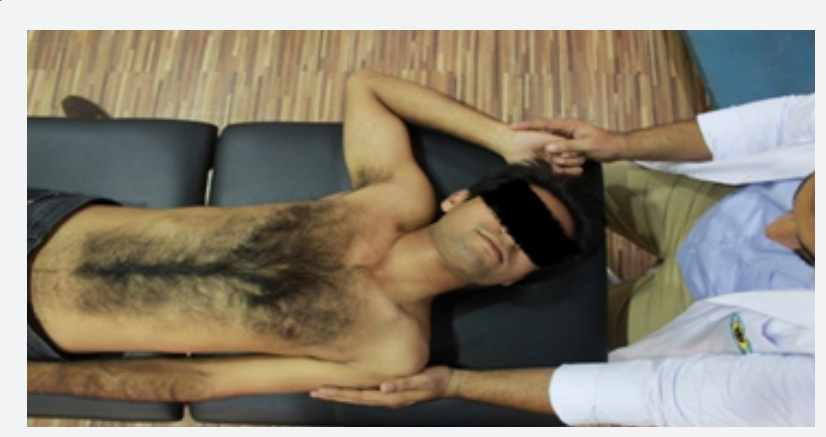

Figure 2: Treatment duration: 3 sessions per week for 4 weeks.

Application of PRT-Total 20 subjects was given Positional Release technique. The subject was in supine with therapist sitting on the affected side, trigger points were located along the upper fibers of the trapezius. The subject's head was laterally flexed toward the side of trigger point, then therapist grasps the subject's forearm and abducts shoulder to approximately $90^{\circ}$ and adds slight flexion or extension to fine-tune. The ideal position of comfort achieved was held for a period of 90 seconds and followed by a passive return of the body part to an anatomically neutral position continued for 5 minutes (Figure 2). Treatment duration: 3 sessions per week for 4 weeks [17]. Data were stored and analyzed using SPSS, version 16.0 , count and percentages were reported for gender, and number of patients enrolled in each technique, mean and standard deviation were reported for age, duration of pain, cervical range of motions at pre- post treatment, and NRS scores, paired sample t-test was used to compare the mean levels of pre and post treatment and independent sample t-test was used to compare the post mean scores of PRT and INIT patients, p-values less than 0.05 were considered as significant. Pie and Bar chart were also used to give the graphical presentation of mean scores (Figure 3).

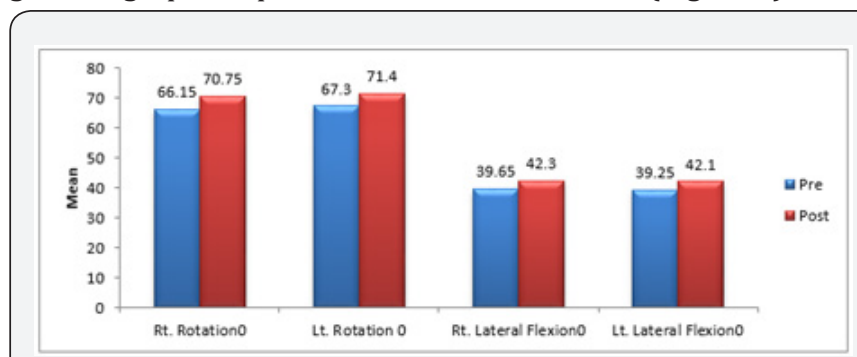

Figure 3: Mean Comparisons of Cervical Movements of PRT Patients at Pre and Post Level of Treatment.

Table 1: Baseline Characteristics of Studied Samples $(n=40)$.

\begin{tabular}{|c|c|c|c|}
\hline \multicolumn{2}{|c|}{ Characteristics } & n & \% \\
\hline \multirow{2}{*}{ Gender } & Male & 8 & 20 \\
\cline { 2 - 4 } & Female & 32 & 80 \\
\hline \multirow{2}{*}{ Technique } & PRT & 20 & 50 \\
\cline { 2 - 4 } & INIT & 20 & 50 \\
\hline Age (Years) & Mean, SD & 20.92 & 3.82 \\
\hline Pain Duration (months) & Mean, SD & 1.43 & 1.15 \\
\hline
\end{tabular}

Table 2: Mean Comparisons of Cervical Movements of INIT Patients at Pre and Post Level of Treatment.

\begin{tabular}{|c|c|c|c|c|c|}
\hline \multirow{2}{*}{$\begin{array}{c}\text { Cervical } \\
\text { Movements }\end{array}$} & \multicolumn{2}{|c|}{ Pre } & \multicolumn{2}{c|}{ Post } & \multirow{2}{*}{ p-value } \\
\cline { 2 - 6 } & Mean & SD & Mean & SD & \\
\hline Rt. Rotation0 & 63.6 & 5.67 & 73.4 & 2.77 & $<0.01^{*}$ \\
\hline Lt. Rotation 0 & 65 & 3.91 & 73.15 & 2.65 & $<0.01^{*}$ \\
\hline Rt. Lateral Flexion0 & 38.85 & 2.69 & 43.15 & 0.94 & $<0.01^{*}$ \\
\hline Lt. Lateral Flexion0 & 39.6 & 2.73 & 43.4 & 1.43 & $<0.01^{*}$ \\
\hline & ${ }^{*}$ < $<0.05$ was considered significant using Paired Sample t-test \\
\hline
\end{tabular}

Table 3: Mean Comparisons of NRS Scores of PRT and INIT Patients at Pre and Post Level of Treatment.

\begin{tabular}{|c|c|c|c|c|c|}
\hline \multirow{2}{*}{ NPR Scores } & \multicolumn{2}{|c|}{ Pre } & \multicolumn{2}{c|}{ Post } & \multirow{2}{*}{ p-value } \\
\cline { 2 - 6 } & Mean & SD & Mean & SD & \\
\hline PRT Patients $(\mathrm{n}=20)$ & 4.05 & 0.76 & 2.25 & 0.79 & $<0.01^{*}$ \\
\hline INIT Patients $(\mathrm{n}=20)$ & 4.4 & 1.1 & 1.4 & 0.76 & $<0.01^{*}$ \\
\hline & $* \mathrm{p}<0.05$ was considered significant using Paired Sample t-test \\
\hline
\end{tabular}


Table 1 gives the baseline characteristics of studied sample, in the following study total forty sample were enrolled, $80 \%$ were female samples, patients equally divided into two treatment groups of PRT and INIT, the mean age of samples was $20.92 \pm 3.82$ years and the mean pain duration was $1.43 \pm 1.15$ months. (Table 2) reports the mean and standard deviations of cervical moments among PRT treated patients at pre and post levels, results showed that, right rotation, left rotation, right lateral flexion and left lateral flexion were significantly improved after the treatment with p-values less than 0.01 . (Table 3 ) reports the mean and standard deviations of cervical moments among INIT treated patients at pre and post levels, results showed that, right rotation before treatment was 65.6 degree and after treatment it was 73.4 degree, significantly improved, left rotation before treatment was 65 degree and after treatment it was 73.15 degree, similarly right and left flexion rotation were significantly improved after the INIT treatment with p-values less than 0.01 . Figure 4 gives the mean comparison of NRS scores among PRT and INIT patients, results showed, among PRT patients NRS before treatment was $4.05 \pm 0.76$ and after treatment it went down significantly to $2.25 \pm 0.79$, similarly among INIT patients mean NRS was $4.4 \pm 1.1$ and after treatment it was $1.4 \pm 0.76$ and differences were statistically significant with p-value less than 0.05 Figure 5 gives the post mean comparisons of cervical moments and NRS scores between PRT and INIT techniques results showed that, right rotation significantly get improved among INIT patients, right lateral flexion and left lateral flexion were also significantly improved among INIT patients, however left rotation did not give any significant differences between PRT and INIT techniques, the mean NRS scores was significantly low among INIT patients as compared to PRT patients with p-value less than 0.05 .

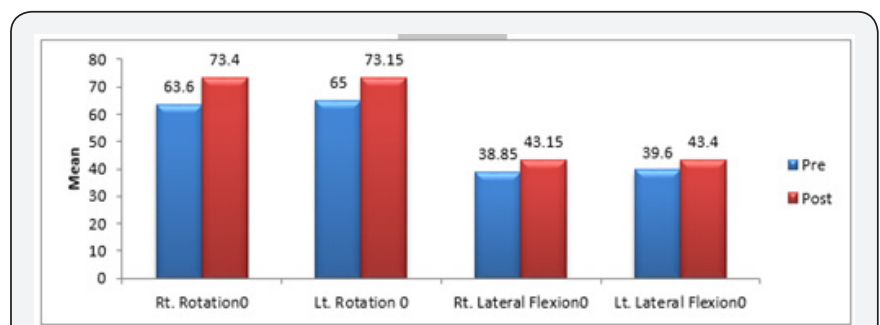

Figure 4: Mean Comparisons of Cervical Movements of INIT Patients at Pre and Post Level of Treatment.

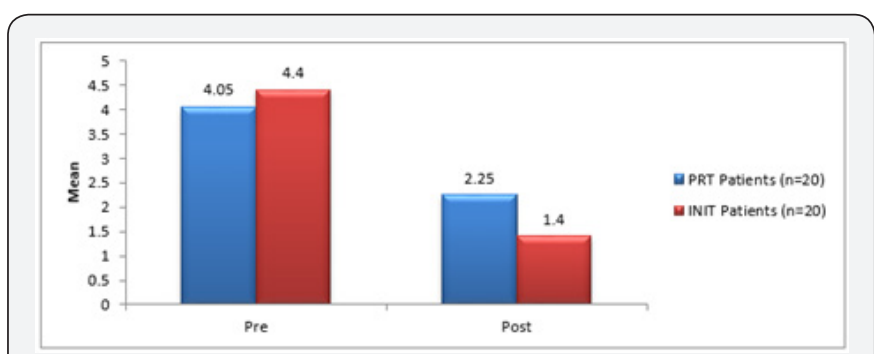

Figure 5: Mean Comparisons of NRS Scores of PRT and INIT Patients at Pre and Post Level of Treatment.

\section{Discussion}

Study conducted by Mrs. B. Jyothirmai et al. on patients with Upper Trapezius Trigger points in order to identify the sufficiency of INIT separately and INIT close by quality getting ready in upper trapezius trigger point patients. The study findings showed that Upper trapezius trigger point's results in the neck torment with impediment in range of motion of cervical and extended insufficiency. Neck disability index also indicates that, independently both test and control aggregate were observed to be powerful in decreasing torment and enhancing range of motion of cervical and lessening the disability of neck. Whereas when the two groups were analyzed, there was a huge change in test assemble with more prominent mean as compared to the control group [18]. In the following study results showed that right side cervical bending was improved by 38.85 to 43.15 and left side cervical bending was improved by 39.6 to 43.4 and right-side cervical rotation by 63.6 to 73.4 and left cervical rotation was improved by 65 to 73.15 .

\section{Conclusion}

It has been concluded from the study that both the techniques INIT and PRT were found to be effective in the treatment of upper Trapezius Trigger points. Significant improvement was seen in the symptoms of patient with the increase in cervical range of motion and reduction in pain. The study further concluded that INIT was found to be more effective as compared to PRT in the patients with Upper Trapezius trigger points.

\section{References}

1. Johnson G, Bogduk N, Nowitzke A, House D (1994) Anatomy and actions of the trapezius muscle. Clinical biomechanics 9(1): 44-50.

2. Delgado VE, Romero CJ, Escoda GC (2009) Myofascial pain syndrome associated with trigger points. Oral Medicine and Pathology Publication Type 14(10): 494-498.

3. Han SC, Harrison P (1997) Myofascial pain syndrome and trigger-point management. Reg Anesth 22(1): 89-101.

4. CZ H, TU H (1996) Difference in pain relief after trigger point injections in myofascial pain patients with and without fibromyalgia. Arch Phys Med Rehabil 77(11): 1161-1166.

5. FW L, JC S (1993) Use of trigger point injections in chronic pelvic pain. Obstet Gynecol Clin North Am 20(4): 809-815.

6. David G, Simons MD (1987) Myofascial Pain Syndrome Due to Trigger Points. IRMA Monograph Series p. 1-39.

7. Shah PJ, Gilliams AE (2008) Uncovering the biochemical milieu of myofascial trigger points using in vivo microdialysis. J Bodyw Mov Ther 12(4): 371-384.

8. Travell, Janet, Simons David, Simons Lois (1999) Myofascial Pain and Dysfunction: The Trigger Point Manual $2^{\text {nd }}$ Edn. Lippincott Williams \& Williams, USA p. 2.

9. Pillay G M (2003) The treatment of myofascial pain syndrome using therapeutic ultrasound, on upper trapezius trigger points: A double-blinded placebo controlled study comparing the pulsed and continuous waveforms of ultrasound. 
10. Wong KC (2012) Strain Counter strain: Current concepts and clinical evidence. Manual Therapy 17(1): 2-8.

11. Speicher T, Draper OD (2006) Top 10 Positional-Release Therapy Techniques to Break the Chain of Pain. Physical Therapy \& Human Movement Science 1(1): 60-62.

12. Leon Chaitow (2000) Modern Neuromuscular Techniques by Churchill Livingstone. Muscle Energy Techniques by Leon Chaitow, $2^{\text {nd }}$ Edn, 2001 Published by Churchill Livingstone.

13. Abha Sharma R, Angusamy, Sumit Kalra, Sukhmeet Singh (2010) Ef ficacy of post-isometric relaxation versus integrated neuromuscular ischaemic technique in the treatment of upper trapezius trigger points.

14. Rana DP, Brahmbhatt B (2017) Effect of muscle energy technique versus positional release technique in computer workers with upper trapezius muscle spasm: A comparative study. International Journal of Multidisciplinary Research and Development 4(5): 29-23.
15. Wakde P, Anap D (2016) Effectiveness of Integrated neuromuscular inhibitory technique in sub-acute trapezitis. VIMS Physiotherapy Journal of Case Reports 1(1): 11-15.

16. Nagrale VA, Glynn P, Joshi A, Gopichand Ramteke G (2010) The efficacy of an integrated neuromuscular inhibition technique on upper trapezius triggers points in subjects with non-specific neck pain: a randomized controlled trial. J Man Manip Ther 18(1): 37-43.

17. Rana DP Brahmbhatt B (2017) Effect of muscle energy technique versus positional release technique in computer workers with upper trapezius muscle spasm: A comparative study. International Journal of Multidisciplinary Research and Development 4(5): 23-29.

18. Jyothirmai B, Kumar SK, Raghav krishna S, Madhavi K (2015) Effectiveness of Integrated Neuromuscular Inhibitory Technique (Init) with Specific Strength Training Exercises in Subjects with Upper Trapezius Trigger Points. International Journal of Physiotherapy 2(5): 759-764.

\section{Your next submission with Juniper Publishers} will reach you the below assets

- Quality Editorial service

- Swift Peer Review

- Reprints availability

- E-prints Service

- Manuscript Podcast for convenient understanding

- Global attainment for your research

- Manuscript accessibility in different formats

( Pdf, E-pub, Full Text, Audio)

- Unceasing customer service

Track the below URL for one-step submission https://juniperpublishers.com/online-submission.php 